\title{
Cartas pessoais entre crianças brasileiras, portuguesas e angolanas
}

\author{
Personal letters between Brazilian, Portuguese and \\ Angolan children
}

\section{Les lettres personnelles entre les enfants brésiliens, portugais et angolais}

Dagoberto BUIM ARENA

Sonia OLIVEIRA SANTOS

Stela MILLER

\section{RESUMO}

Este artigo analisa os resultados de dados obtidos pela realização, entre 2008 e 2009 , de projeto de extensão e de pesquisa relativo à troca de cartas internacionais entre professores e alunos de escolas de ensino fundamental das cidades de Garça e Marília, Estado de São Paulo, Brasil, com uma escola na cidade de Azaruja, em Portugal e outra na cidade de Luanda, Angola. Foi desenvolvido por equipe de alunos e professores dá UNESP de Marília, com a finalidade de promover o intercâmbio por meió de cartas pessoais, para que os alunos, entre 8 e 9 anos de idade, pudessem se apropriar da língua escrita, no caso a portuguesa, e compreendê-la como instrumento impregnado da cultura. A escolha desse gênero, no universo do gênero epistolar, foi feita por propiciar a participação do outro na configuração de relações dialógicas de construção de enunciados, tomadas como referência em uma concepção bakhtiniana de linguagem. Teve como objetivos (1) apontar, nas cartas trocadas, entre professores, e entre os alunos portugueses, brasileiros e angolanos, nos primeiros anos escolares, os indícios de assunção de condutas linguísticas de autoria que poderiam sinalizar o início da autonomia no uso da modalidade escrita de linguagem, ou indícios de condutas de submissão; (2) revelar os instrumentos linguísticos de teor cultural utilizados na construção de enunciados indicadores dos costumes de cada povo, entre eles os que constituem os fazeres escolares. Para a geração dos dados foram utilizados princípios de pesquisa-ação, que possibilitaram a ação direta, junto aos professores brasileiros, e indireta, no caso dos docentes estrangeiros. Da análise do corpus da pesquisa - cartas trocadas entre professores e alunos - constata-se que a apropriação da língua como um ato discursivo em realização no seio 
das relações humanas faz da velha correspondência pessoal um instrumento poderoso de evolução no domínio da língua escrita.

Palavras-chave: comunidade escolar lusófona, aprendizagem da língua escrita, gênero epistolar, ensino fundamental.

\begin{abstract}
This article analyzes the data resultant of the accomplishment, between 2008 and 2009, of an extension and research project on the international exchange of letters between teachers and students from elementary schools in the towns of Garça and Marília, São Paulo State, Brazil, with a school in the city of Azaruja, Portugal and another in the city of Luanda, Angola. It was developed by a team of students and teachers, UNESP, Marília, in order to promote the exchange via personal letters for that students, between 8 and 9 years old, could take possession of the written language, in this case Portuguese, and understand it as an instrument steeped in culture. The choice of this kind in the world of the epistolary genre was made because it promotes the participation of the Other in the configuration of dialogic relations in the elaboration of the statements, taken as a reference in a Bakhtinian conception of language. It aimed to (1) point, in the letters exchanged between teachers and students between the Portuguese, Brazilians and Angolans in the early years, the evidence of authorship linguistic behavior that could signal the beginning of autonomy in the use of the written modality of language, or signs of submissive behavior; (2) reveal the cultural content of language tools used to construct indicators listed on the customs of each people, including those constituting school doings. For the generation of data were used principles of action research, which enabled direct action, along with Brazilian teachers, and indirectly, in the case of the foreign teachers. From the analysis of the corpus of research - letters exchanged between teachers and students - it is clear that the appropriation of language as a speech act realized in human relations makes the old personal correspondence a powerful instrument of development in the area of the written language.
\end{abstract}

Index terms: Lusophone community school, learning of the written language, epistolary genre, elementary school

\title{
RÉSUMÉ
}

Cet article analyse les données obtenus, entre 2008 et 2009, dans le projet d'extension et de recherche sur les échanges internationaux de lettres entre enseignants et élèves d'écoles primaires dans les villes de Garça et Marilia (São Paulo, Brésil), avec une école de Azaruja (Portugal) et une de 
Luanda (Angola). Il a été développé par une équipe d'étudiants et d'enseignants, UNESP, Marília, afin de promouvoir l'échange des lettres personnelles afin que des élèves, entre 8 et 9 ans, peuvent prendre possession de la langue écrite le portugais et de la comprendre comme un instrument ancré dans la culture. Le choix de ce genre dans le monde du genre épistolaire, a été fait par la promotion de la participation de l'Autre dans la configuration des relations dialogiques de renforcement des déclarations, pris comme référence dans une conception bakhtinienne du langage. Destiné aux : (1) dans les lettres échangées entre les enseignants et d'étudiants dans les premières années les Portugais, les Brésiliens et les Angolais - font preuve de comportements de création qui pourrait marquer le début d'autonomie dans l'utilisation de la modalité langue écrite, ou un comportement des soumission; (2) mettre en évidence le contenu culturel des outils linguistiques utilisés pour construire les indicateurs figurant sur les habitudes de chaque peuple,et les actions faites à l'école. Pour la génération de données le principe de la recherche-action a été utilisé ce qui a permis l'action directe, avec les enseignants brésiliens, et indirect, avec les enseignants étrangers. L'analyse du corpus de lettres échangées entre des enseignants et des étudiants montre que l'appropriation de la langue comme un acte de parole dans la réalisation de relations humaines au sein de la vieille correspondance personnelle fait un puissant instrument de développement dans le domaine de la langue écrite.

Mots-clés: communauté scolaire lusophone, l'apprentissage de la langue écrite, le genre épistolaire, l'école élémentaire

\section{Introdução}

Entre 2008 e 2009, foi desenvolvido, por uma equipe de alunos e professores da UNESP de Marília, um projeto de extensão e de pesquisa que previa a troca de cartas internacionais entre professores e alunos de escolas de ensino fundamental das cidades de Garça e Marília, no Estado de São Paulo, com uma escola na cidade de Azaruja, em Portugal e outra situada na cidade de Luanda, capital de Angola. O objetivo fundamental do projeto era o de promover o intercâmbio por meio de cartas pessoais para que os alunos pudessem se apropriar da língua escrita, e neste caso, da portuguesa, e compreendê-la como instrumento impregnado da cultura. A utilização do 
gênero carta pessoal, no universo do gênero epistolar, traria para professores e alunos, a ostensiva participação do outro na configuração de relações dialógicas de construção de enunciados, tomadas como referência em uma concepção bakhtiniana de linguagem.

Este artigo, tendo como base os dados obtidos por essa pesquisa e o quadro referencial bakhtiniano, foi organizado com os objetivos de (1) apontar, nas cartas trocadas, entre professores, e entre os alunos portugueses, brasileiros e angolanos, nos primeiros anos escolares, os indícios de assunção de condutas linguísticas de autoria que poderiam sinalizar o início da autonomia no uso da modalidade escrita de linguagem, ou indícios de condutas de submissão, e (2) revelar os instrumentos linguísticos de teor cultural utilizados na construção de enuncilados indicadores dos costumes de cada povo, entre eles os que constituem os fazeres escolares.

Os temas e assuntos tratados durante o desenvolvimento do projeto de extensão e pesquisa não se encaminharam com intensidade para aspectos pessoais; não houve aprofundamento das relações mais íntimas entre o\$ correspondentes, em razão das diferenças de períodos letivos entre os continentes americano, europeu e africano.

O corpus a ser analisado é constituído, no que diz respeito à correspondência mantida com os portugueses, por carta pessoal de $\mathrm{N}$, professora de Garça, endereçada aos alunos de Azaruja, em 2008; a resposta da classe portuguesa, por mediação de M., professora portuguesa; e de algumas cartas trocadas entre alguns alunos brasileiros e portugueses. No que tange à correspondência com o continente angolano, o corpus é constituído de cartas escritas pelos alunos angolanos que iniciaram uma troca de cartas com os correspondentes brasileiros, individualmente, com destinatários escolhidos de uma lista previamente enviada por correspondência eletrônica pela professora brasileira, mas que, infelizmente, foi descontinuada. 
Para a geração dos dados foram utilizados alguns princípios de pesquisa-ação defendidos por Thiollent (1986), Tripp (2005) e Carr e Kemmis (1988), porque esse tipo de pesquisa possibilitou a ação direta junto aos professores, principalmente no caso brasileiro, e de modo indireto com os docentes dos outros países. De acordo com Thiollent (1986, p. 14), a pesquisa-ação:

É um tipo de pesquisa social com base empírica que é concebida e realizada em estreita associação com uma ação ou com a resolução de um problema coletivo e no qual os pesquisadores e os participantes representativos da situação ou do problema estão envolvidos de modo cooperativo ou participativo.

Na situação de provocação de correspondência entre crianças, a ação envolveria um problema coletivo, o de apropriação da língua escrita portuguesa por meio do gênero epistolar, entre crianças de mesma faixa etária - 8 e 9 anos - de escolas no Brasil, em Portugal e em Angola. Ao longo dos trabalhos, os sujeitos - professores e alunos - interagiram e produziram conhecimento, nos três continentes, por meio de suas ações no decorrer das atividades cujo eixo organizador era a escrita de cartas. Nesse processo, os sujeitos desempenharam um papel ativo que levou a mudanças tanto no ambiente escolar como no familiar.

Tripp (2005) considera a pesquisa-ação como "uma estratégia para o desenvolvimento de professores e pesquisadores de modo que eles possam utilizar suas pesquisas para aprimorar seu ensino e, em decorrência, o aprendizado de seus alunos" (TRIPP, 2005, p. 445). Os professores criavam o contexto para intercâmbio com a escrita por meio de uma carta coletiva inicial e, posteriormente, ensinavam e orientavam a elaboração das cartas individuais para satisfazer a necessidade criada - a da troca de informações entre alunos por via postal.

Escrever cartas, como afirma Santos (2010, p. 59), 
[...] ao mesmo tempo em que desenvolve um trabalho prático, possibilita a investigação a respeito do desenvolvimento da escrita e como ocorre a sua apropriação. Esse processo cíclico de pesquisa possibilita buscar na prática as perguntas, procurar na teoria as respostas, e voltar para prática para modificá-la. Esse tipo de pesquisa-ação aprimora a prática no momento de sua produção.

Carr e Kemmis (1988, p. 176), estudiosos da pesquisa-ação, entendem que esse tipo de pesquisa trabalha com os problemas relacionados à aprendizagem, por meio da própria ação e aperfeiçoa as ações de aprendizagem pela própria prática. Para eles, os objetivos das ações de melhoria da situação no interior da pesquisa indicam três fatores importantes:

Primeiro, o aperfeiçoamento da prática; segundo lugar, a melhoria do entendimento da prática por parte de quem a realiza; terceiro, o aperfeiçoamento da situação em que a prática tem lugar (CARR; KEMMIS, 1988, p.177, tradução nossa).

A esperança dos pesquisadores, ao promover as ações de escrita de cartas internacionais junto a professores e alunos era a de proporcionar relações que pudessem, efetivamente, criar necessidades de relações por meio da língua escrita, formatada em um gênero tradicional - o epistolar, via postal - no universo de relações epistolares eletrônicas por e-mail, Facebook, Twitter, Skype, MSN e SMS.

Da leitura das cartas na perspectiva de alguns conceitos propostos por Bakhtin (2003), cinco núcleos temáticos puderam ser observados, tanto nas construídas coletivamente, quanto nas individualmente elaboradas: 1 . tensão entre assumir a autoria ou renunciar a ela; 2. indícios culturais nos enunciados do gênero epistolar; 3. sinais de diversidade cultural de linguagem e de costumes; 4. jogos próprios do mundo infantil; 5. atividades e saberes da cultura escolar. 
Nos próximos tópicos serão feitos comentários a respeito do gênero epistolar e das marcas de autoria que aparecem nesse gênero textual, tendo como referência as cartas escritas conjuntamente pelas professoras e alunos dos países envolvidos na troca de correspondências anunciada.

Em seguida, serão analisadas as cartas trocadas entre Brasil e Portugal - três cartas trocadas pelas professoras de ambos os países, duas cartas de alunos brasileiros, duas de alunos portugueses - e as cartas trocadas entre Brasil e Angola - duas de alunos angolanos. Os comentários sobre as cartas das crianças terão como referência os núcleos temáticos, sem, contudo, organizá-los em tópicos distintos.

\section{Sobre o gênero epistolar}

A orientação teórica dos princípios de Bakhtin (2003) a respejto dos gêneros do discurso destaca o outro como referência fundamental em, sua construção, porque, com o enunciador, o outro constitui o outro pólo do processo dialógico. A língua escrita, objeto de atenções neste trabalho, se manifesta como língua nas relações entre o enunciador que se torna o outro e esse mesmo outro que se transforma em enunciador, por meio de constantes réplicas e tréplicas de um diálogo em construção. Esse outro, para quem se dirige em primeira instância o enunciado, poderia, para Bakhtin (2003), coincidir concretamente com uma pessoa definida, ou ser a representação de definido padrão social.

A presença insubstituível do outro nas escritas das crianças torna-se, frequentemente, imenso desafio para professores. Como a língua, na concepção bakhtiniana, se realiza nos gêneros dos discursos, em padrões relativamente estáveis, mas que permitem a sua própria reinvenção, nada se manifesta mais difícil para o professor que ensinar as crianças a ter o outro no horizonte de sua criação textual. Faltam, na escola, por razões específicas de seu fazer com a linguagem escrita, os contextos, o outro, as finalidades, 
os motivos e as necessidades. Mesmo a idealização do outro como referente social de uma época, de um grupo social, de uma faixa etária, passa a ser de estranha construção no interior de uma instituição que foi incumbida mais como a responsável por ensinar a palavra e a oração gramaticais, do que ensinar a língua sempre plena de enunciados culturais nas relações humanas.

Os esforços para materializar a figura do outro, ou como afirma Bakhtin, para "coincidir pessoalmente" o destinatário e a figura real de alguém, esbarram na natureza do gênero escolhido para satisfazer a necessidade artificialmente criada nas relações que compõem a cultura escolar. A natureza do gênero pode distanciar ou aproximar o outro do enunciador: no conto fantástico escrito por ủma criança, o horizonte pode ser preenchido pela figura do professor-avaliador, mas na velha carta pessoal, o outro se materializa, em graus múltiplos e por meio de recursos vários: o conhecimento anteriormente revelado, um fotografia, um nome, uma condição escolar.

Por limitação das condições financeiras para o procedimento de envio de cartas diretamente para o endereço dos alunos, a única opção foi a de enviar cartas individuais, acompanhadas por uma carta pessoal da professora de uma das turmas, no interior de um grande envelope, destinado diretamente para o endereço institucional das escolas, aos cuidados da professora responsável pela classe. Esse procedimento, de qualquer forma, poderia proporcionar a rara oportunidade de correspondência entre crianças brasileiras, portuguesas e angolanas, aprendizes de países de mesma língua e, por meio do papel como suporte, romper as fronteiras de seu mundo cultural, mesmo em tempos de utilização intensa de mensagens eletrônicas.

Ao colocar em ação este projeto em Marília, a equipe de trabalho expressava três intenções principais: a de promover a inserção da universidade na rede de escolas de ensino fundamental, para contemplar a interação entre os sistemas educacionais; a de investigar aspectos relacionados à apropriação da linguagem escrita, plena de sentido e de 
cultura; e o de proporcionar às crianças a oportunidade de conhecer colegas do país colonizador e dos colonizados, e, de ambos, particularidades de seu país, seus costumes culinários, suas brincadeiras infantis, suas manifestações sociais, seus assuntos escolares e os usos de expressões diferenciadas de linguagem.

Uma das preocupações durante a troca de cartas situava-se no desenvolvimento do conceito de nação, de país e de alguns de seus constituintes, como a língua, e das fronteiras demarcadas em um lugar geográfico ocupado no globo terrestre. Havia ainda a curiosidade inicial, entre os alunos, de entender as relações entre mares e continentes, e compreender o modo como as pessoas se deslocam entre países distantes. No caso brasileiro, os escolares conhecem Portugal por meio dos dados históricos ligados à chegada dos navegadores, do trabalho catequista dos jesuítas, da Inconfidência em Minas, do deslocamento da corte portuguesa em fuga durante invasão napoleônica, e, talvez, da figura de Pedro I como libertador. Esses fatos históricos para as crianças são apenas referências de um país distante, tanto histórica quanto geograficamente. A correspondência com crianças portuguesas daria vida a um país com imagem envelhecida e o traria para bem perto das crianças brasileiras.

Se assim poderiam pensar as crianças brasileiras, pouco poderia se imaginar sobre o que pensariam os miúdos portugueses e quais seriam suas impressões sobre o Brasil. Com a mediação de uma professora da Universidade de Évora, em Portugal, e de $\mathbf{S}$, uma de suas alunas de PósGraduação, mas moradora em Luanda, foi possível estabelecer contatos com uma escola pública angolana com o mesmo objetivo, todavia as condições foram muito mais adversas que as enfrentadas na relação com Portugal.

Depois de muitos contatos eletrônicos com S., também mãe de um dos alunos da escola de Luanda, chegou à escola Garça, no Brasil, um envelope com muitas cartas, caprichosamente escritas, endereçadas diretamente aos alunos. Foi interessante verificar que o envelope havia sido 
postado em São Paulo, possivelmente por algum angolano que para o Brasil tenha viajado e por essa razão tivesse se tornado portador do envelope. A confirmação de que a via postal não funcionava muito bem foi constatada após as respostas elaboradas pelas crianças brasileiras: jamais houve outro contato postal, nem foi possível restabelecer os contatos eletrônicos porque o destinatário, mediador inicial, não atendia aos chamados via internet.

Mesmo com a frustração motivada pela interrupção da correspondência, há dados interessantes que podem alimentar a análise das relações culturais e linguísticas, pela escrita, em gênero epistolar colocado em prática pelas crianças dos três países de língua portuguesa. A estruturação deste artigo prevê descrições mais detalhadas da metodologia, da qual alguns procedimentos foram já anunciados; a organização dos dados em núcleos temáticos; a análise desses núcleos apoiada principalmente nos estudos bakhtinianos, e, ao final, a conclusão.

\section{Tensão entre a autoria e a sua diluição}

Compreendida como gênero primário, por ser construída nas relações do cotidiano, as cartas pessoais são as manifestações linguístjcas exemplares do movimento criativo da língua nas relações humanas. Pelos enunciados constitutivos desse gênero, os interlocutores e destinatários, ora uns ocupando a posição de outros e ora outros assumindo o papel de uns, deixam suas marcas de autoria, ou deveriam deixá-las, porque nenhum gênero é tão necessitado de autoria quanto a carta. Em uma carta pessoal deveriam jorrar marcas de autoria, mas nem sempre essa orientação foi feita nas atividades escolares, porque os modelos padronizados substituíram ou domesticaram, de certo modo, os arroubos do enunciador. Apesar dos tempos distantes, muitos na geração acima dos cinquenta anos se lembram da célebre introdução, encontrada em cadernos em escolas de todo o país, com pequenas variações: Espero que esta vá encontrá-lo com muita 
felicidade e saúde junto aos seus. Atualmente podemos não encontrar algo dessa natureza nas cartas dos escolares, mas, muito provavelmente, outros indícios atestarão formas de padronização, historicamente constituídas, nas correspondências dos alunos.

Os dilemas da autoria se manifestam e são causados pela relação de poder no uso da língua. Ensinados como oração gramatical, resta pouco espaço para os enunciados plenos de cultura e significado, mesmo nos gêneros do discurso que são escritos no cotidiano, como as cartas pessoais. A autonomia para transformar as palavras alheias em palavras próprias (BAKHTIN, 2003), no mundo dos que aprendem a escrever, ainda é uma conquista árdua, portanto, assumir a autoria nos primeiros escritos de gêneros razoavelmente estáveis é uma atitude ainda de alto risco diante do outro muito bem definido, como é o destinatário de uma carta. A tensão entre assumir a autoria ou renunciar a ela é o dilema que enfrenta o enunciador diante do professor que ensina, e diante do destinatário que se coloca em atitude responsiva. Ser autor solitário ou compartilhar a autoria em obediência a padrões já engessados de escrita é a atitude desestabilizadora que corrói a escolha do tema, do estilo e da composição do gênero (BAKHTIN, 2003) pelo enunciador.

\section{As cartas entre Brasil e Portugal}

Inicialmente apresentaremos duas cartas construídas coletivamente entre professora e alunos que foram enviadas de Portugal, e uma enviada pela professora brasileira para aquele país.

A primeira carta vinda de Portugal, escrita em 12 de março de 2008, em computador, assinada por todos os alunos da classe composta por alunos de $3^{\circ}$ e de $4^{\circ}$ anos, indicava a recepção da primeira carta enviada de Garça. Convém destacar que todas as transcrições de textos das cartas respeitarão a 
ortografia, pontuação e construção feitas por professores e crianças, tanto do Brasil, quanto de Portugal e de Angola.

Diz a carta:

Olá turma da professora N.! Recebemos a vossa carta e gostamos muito dos auto-retratos. Achámos os vossos nomes um pouco diferente dos nossos. Nós somos 19 alunos, 8 raparigas e 11 rapazes do $3^{\circ}$ e $4^{\circ}$ ano de escolaridade. No dia 21 de março começa a Primavera no nosso país e no vosso deve ser o Outono. A partir do dia 14 deste mês vamos ter 15 dias de férias. São as férias da Páscoa. Já percebemos que vocês aí têm um sistema de aulas diferente do nosso. Nós começamos as aulas em Setembro e acabamos em Junho. A nossa terra é uma vila do distrito de Évora que fica no Alentejo. Vamos ficar a corresponder-nos com muito gosto. Até a próxima! Os vossos amigos de Azaruja.

Endereçada a uma turma de alunos, a carta acima transcrita dilui o processo de construção de autoria personalizada. Há uma tensão subjacente entre a professora que coordena a interlocução na sala de aula com questồes sobre o quê e como iriam escrever para os amigos do Brasil. A professora assume o giz, inicialmente, depois o computador para a construção doß enunciados que seriam remetidos em direção às crianças brasileiras.' As crianças portuguesas supostamente colaboram com sugestões, junto com a docente, a-respeito do conteúdo a ser escrito: os només estranhos, a diferença de estações, os períodos de férias e a localização da pequena vila. A tensão para definir a autoria é estabelecida pela natureza coletiva da construção da carta, no caso, estritamente direcionada pela figura do professor quanto às escolhas formais do dizer. A natureza individual da escrita, por seu lado, pode permitir a assunção da autoria, mas depende, para sua afirmação, das relações mantidas entre professor e alunos, entre permitir e determinar.

A língua escrita em enunciados, vista pelo olhar de Bakhtin (2003), traz com ela e por meio deles, os traços da cultura de um povo e da própria 
cultura escolar. Indícios disso encontram-se na utilização de nomes clássicos em Portugal, em contraposição às diferentes construções ou das adaptações de nomes americanos no Brasil, considerados "um pouco diferente" pelas crianças portuguesas. Certamente a mesma estranheza seria causada nos alunos brasileiros o termo "rapariga" para designar o nosso termo usual "menina" e "rapazes" para "meninos". Como alerta Bakhtin (1990, p. 62, grifos no original), “o signo e a situação social em que se insere estão indissoluvelmente ligados. O signo não pode ser separado da situação social sem ver alterada sua natureza semiótica." No Brasil, as relações materiais de vida consagraram outros significados para essas mesmas palavras. Em acréscimo, a cultura escolar, com suas marcas próprias, introduz a polêmica sobre a diversidade, o diferente, o estranho, particularmente sobre a organização do ano letivo, e especialmente para a criança brasileira acostumada com a coincidência entre ano escolar e ano civil. Decorrente dessa forma divergente de estruturação do ano letivo entre os dois países, os períodos de descanso entre aulas são também assunto para as trocas de informações: 15 dias de descanso no período da Páscoa para o\$ alunos portugueses constitui uma novidade para as crianças brasileirası, Da mesma forma, constituem novidades a existência de duas séries_em uma mesma sala e o total de alunos por sala, bem maior no Brasil que o grupo dos 19 interlocutores de Azaruja. Todas essas informações, que traduzem aspectos culturais característicos de um grupo social determinado, constituem indicadores dos costumes historicamente desenvolvidos, veiculados por meio de enunciados produzidos pelos usuários da língua, neste caso, a escrita.

A carta abaixo, escrita em 20 de junho de 2008, com traços caligráficos diferenciados, indicando escrita a muitas mãos, anunciava a despedida no final do ano letivo português: 
Olá alunos da professora N! Hoje é o nosso ultimo dia de aulas. Aprendemos muito com a nossa correspondência: receitas de bolos, sumos, conhecemos a festa da Cereja em Garça, que os vossos nomes são diferentes dos nossos e o clima é muito diferentes do nosso também. Hoje estamos a começar o Verão e vocês começam o Inverno. Ficamos muito contentes por nos correspondermos com vocês. Adeus até para o ano. Adeus!

Depois das dezenove assinaturas dos alunos, havia, no final da página, outro endereçamento pessoal entre as professoras.

N., gostei muito de si. Só pode ser uma pessoa adorável. Vou conseguir correspondentes para o próximo ano lectivo. Prometo! Um forte abraço, M.

Nesta segunda carta, as trocas culturais são explícitas: a culinária, as festas populares, o modo de viver em climas diferentes na mesma altura do ano. A atitude responsiva do outro - uma turma de alunos - exige novos enunciados, solicita a inclusão de outros elementos culturais que provocarão, por sua vez, eventos de interlocução oral em cada sala onde a correspondência for aberta, com sequências no ano seguinte em decorrência do entusiasmo de uma das professoras que se afastaria para exercer outras funções, mas que prometia a continuidade, como de fato aconteceu, conforme veremos adiante.

Mais na primeira que na segunda carta, é possível perceber o estranhamento que deve ter causado à criança brasileira o uso do pronome vosso, que convive, na escrita das crianças portuguesas, com o pronome de tratamento "vocês" e não "vós" na posição de sujeito das orações. Não só isso, mas também o uso da preposição junto com o infinitivo, em vez do gerúndio - a começar; a palavra sumo em vez de suco; auto-retratos, por fotografias pessoais, o acento agudo para indicar o pretérito em achámos e o uso da expressão Adeus para despedida.

Em 30 de outubro de 2008, a professora brasileira N. escreveu para outra turma da escola portuguesa: 
Olá pessoal da $1^{\mathrm{a}}$ e $2^{\mathrm{a}}$ séries! O meu nome é N.S.C. Sou professora da $2^{\text {a }}$. Série do Ensino Fundamental aqui na cidade de Garça, estado de São Paulo, Brasil. Minha turma é formada por 31 crianças com 8 anos. Elas escreveram cartinhas para vocês. Espero que gostem. Alguns alunos ainda não escreveram, mas o farão em breve. Escrevam contando como são as coisas por aí. Obrigado, Profa. N.

Somente em 26 de fevereiro de 2009, houve uma resposta coletiva a essa carta, manuscrita, organizada pela professora, com assinaturas de 15 alunos. Essa carta recebida veio acompanhada por vários documentos: uma foto da professora com a sua turma, fotos dos cartazes feitos em sala sobre o tema Carnaval e São Valentim, e uma Abada (conjunto) de Histórias (reescritas de uma história somente por meio de muitos diálogos e algumas curtas interferências de um narrador). No corpo da carta, há destaque para a festa de S. Valentim, sem referência direta no Brasil, e a diferença, do ponto de vista cultural, acerca de como os dois povos - especialmente as crianças - experimentam o período carnavalesco no interior da escola e nas ruas. Exceto pelo fato de que as crianças de lá e de cá ficam sem aulas no período do Carnaval, como indica o trecho da carta "Hoje retomamos as aulas depois de uma pausa de três dias, que foram as férias do Carnaval". No mais, os festejos têm características muito próprias em cada país:

Nós aqui viemos mascarados de acordo com o tema do nosso projecto "Cultura e Civilizações". Alguns vieram de chineses, de mexicanos, índios, espanholas, cowboys, etc. Houve um concurso para eleger a melhor máscara, um desfile e um baile de máscaras. Estávamos todos muito elegantes!

A correspondência, neste caso, incorpora a cultura escolar e seus fazeres, os costumes da tradição popular e a articulação com os conteúdos escolares. Encharcados de cultura, os enunciados encontram o outro - uma turma de alunos - a exigir atitudes de surpresa, curiosidade, perguntas, 
hipóteses, estranhamento, reparos, de um lado e de outro, em provocador fluxo de linguagem.

Entre as tantas cartas trocadas pelas crianças entre 8 e 9 anos, mais ou menos, entre Garça e Azaruja, quatro delas - duas de crianças brasileiras e duas de crianças portuguesas - foram selecionadas para aqui serem transcritas por revelarem aspectos da própria cultura infantil - as brincadeiras, as comidas, as festas, os pequenos animais e sua relação com a organização escolar. Percebe-se, entretanto, a mesma tensão entre assumir a autoria e renunciar a ela para dar espaços a sugestões docentes. Essa percepção pode ser verificada ao serem comparados os temas recorrentes e as mesmas perguntas inscritas em quase todas as cartas trocadas. Não há mesmo, nesses períodos iniciais de ensino da carta pessoal, razões pára o afastamento do docente. Nesses momentos ocorrem as práticas, por meio da linguagem, no processo indicado por Bakhtin de apropriação e transformação das palavras alheias "como minha palavra, porque, uma vez que eu opero com ela em uma situação determinada, ela já está compenetrada de minha expressão" (BAKHTIN, 2003, p. 294).

A composição do gênero tradicionalmente construído, seus temà e a definição clara do outro no horizonte criam as condições contextuais para que o enunciador selecione, no limite de sua autonomia, temas, palavras, construções linguísticas e tente estabelecer controle ortográfico ao realizar duas ou três versões até chegar à final e ao envelope que a transportará.

As duas cartas trocadas entre $\mathrm{S}$ e $\mathrm{L}$, duas meninas, introduzem o tema das brincadeiras e das comidas de cada lugar.

Garça, 23 de outubro de 2008

Olá L. tudo bem?

Meu nome é S. tenho uma irmã de 2 ano e otra bebezinha. É legal sua cidade como ela é? Você sabe bricar de pega-pega e assim: você vai ter que corre e um pega se ele pego e ta com ele. Minha cidade é muito legal. 
Tchau e ate a próxima. (um coração cercado com flores encerra a carta com grande quadro)

$\mathrm{L}$ responde a $\mathrm{S}$ quase dois meses depois da partida da carta do Brasil.

\begin{abstract}
Azaruja, 11 de dezembro de 2008
Olá S tudo bem?

Comingo está tudo bem. Fiquei muito contente com a tua carta. A minha terra é bonita, é pequena e tem poucas pessoas. Eu sei brincar ao pega-pega mas cá chamamos apanha. O meu jogo preferido é beijo e o estalo. Como se festeja aí o Natal? Cá o Natal festeja-se assim: jantamos bacalhau e peru e depois da meia-noite vamos abrir as prendas e vamos à missa do galo.

Tchau, e até à próxima!
\end{abstract}

O tema brincadeira introduzido por $\mathrm{S}$ é aceito por $\mathrm{L}$ ao fázer contraponto ao nome português do pega-pega brasileiro e ao nome jogo em vez de brincadeira. Por outro olhar, há também diferenças sintáticas em relação ao emprego da preposição: em Garça brinca-se de pega-pega a mas em Azaruja joga-se ao apanha ou ao beijo e estalo. A proximidade do Natal, acompanhado do clima gelado do Alentejo, motiva as crianças azarujenses a comentar sobre as prendas a receber, as receitas de bacalhau é de peru a degustar e as obrigações religiosas a cumprir. Infelizmente, as férias de verão no Brasil e o início do ano letivo já com as turmas reorganizadas não permitiram que os miúdos portugueses eńtendessem que em Garça as crianças esperam ansiosos os brinquedos, em vez de prendas, e que a comida varia entre porções assadas de porco ou frango, ou churrascos regados a muito refrigerante para crianças e cerveja para os adultos.

Exceto a palavra comingo, não há outro erro ortográfico nem de concordância na carta de L, supostamente bem supervisionada pela professora, que, apesar de controlar a forma do dizer, respeita as escolhas menos formais do aluno - como o uso do tu e não do vós; o uso de tchau e não de adeus, diferentemente da carta coletiva direcionada formalmente pela 
professora que utilizava a segunda do plural, mais formal - possibilitando maior grau de autonomia e, por extensão, de exercício de autoria pelo aluno.

Um exemplo mais enfático do uso da segunda pessoa do singular com obediência gramaticalmente correta à conjugação verbal encontra-se na carta que $\mathrm{V}$ escreve para $\mathrm{M}$, do Brasil, em resposta a sua carta.

M escreveu em 23 de outubro de 2008, de Garça, para V de Azaruja:

Garça, 23 de outubro de 2008

Olá V

$\mathrm{O}$ meu nome é $\mathrm{M}$ eu estudo na segunda série $2^{\mathrm{a}}$ a minha professora se chama N.S.C. e ela é muito legal. Aí em Portugal é legal? Eu queria conhecer lá. Vocês correspondem com algumas pessoas de outro lugares? Eu correspondi na primeira com Marília e eu fui la conhecer. $\mathrm{Eu}$ me correspondia com uma menina e você correspondeu com Marília e já foi conhecer. Sim ou não? Tchau

Ass. M.P.

Em 11 de dezembro do mesmo ano, $\mathrm{V}$ responde a $\mathrm{M}$ :

Olá M,

Eu estudo no $2^{\circ}$. Ano, a minha professora chama-se LP é boa, mas às vezes ralha comigo porque eu estou desatento. Eu gostava de conhecer o Brasil. Só me correspondo contigo. Quantos anos tens? Eu tenho 8 anos. Qual é a tua brincadeira preferida? Como comemoras o Natal? O que fazes nas férías?

Tchau

$\mathrm{V}$

Especialmente o trecho "Quantos anos tens? Eu tenho 8 anos. Qual é a tua brincadeira preferida? Como comemoras o Natal? O que fazes nas férias?" mostra a forma como V se apropriou de uma forma verbal típica do meio em que vive, e o faz com muita precisão. Diferentemente, M emprega o popular você do português brasileiro com conjugação verbal que corresponde à terceira pessoa. Além disso, destaca-se a ambiguidade, durante o processo de apropriação das noções de espaço, na utilização do advérbio por $\mathrm{M}$ ao indicar a vontade de conhecer "lá", ao referir-se a 
Portugal, por não conseguir entender o outro como situado no lugar "aí". Aos olhos da criança portuguesa, o seu correspondente brasileiro estaria também escrevendo um "mau" português, ora pela ausência de pronomes, ora pelos escorregões de concordância nominal, ora pela confusão entre pronomes pessoais e forma verbal.

No processo realizado na escola brasileira, há escritas e reescritas, mas as crianças tinham a autonomia para tomar a decisão de enviar o texto final, mesmo com incorreções como marcas de autoria em construção e de apropriação da língua escrita como modalidade distanciada das construções orais.

Essas cartas revelam o processo de apropriação da língua esçrita portuguesa, por crianças de dois países situados em continentes e hemisférios diversos, entre colonizador e colonizado, e, por essa razão, dois mundos culturais que impregnam o signo linguístico de cultura, de vida em processo explícito de enunciação, orientado pela existência do outro definido no horizonte das relações humanas infantis. Exemplos disso são os vocábulos diferentes utilizados para expressar uma mesma situação, quando a professora desaprova a conduta desatenta de seu aluno: em Portugal, é usual a professar ralhar com o aluno por ele estar desatento (como foi mencionado na carta de $\mathrm{V}$ a M); enquanto no Brasil a professora fica brava porque o aluno não está prestando atenção. As crianças, como alunos, se apropriam da linguagem do outro, nas relações culturais e sociais, como apontaram Bakhtin (2003) e Vigostki (2001).

\section{As cartas entre Brasil e Angola}

De uma só vez, como anunciado no início deste artigo, chegaram as cartas de Luanda, caprichosamente escritas, encerradas por uma pequena foto três por quatro dos remetentes. A impossibilidade da continuação das trocas, supostamente motivada pela ineficiência dos serviços postais, 
impediu que os desejos, as necessidades criadas, as informações tivessem melhor fluxo. Trinta e três cartas foram recebidas, todas respondidas, mas não houve continuidade. Foram selecionadas duas, apenas, uma na íntegra e outra com destaque de alguns trechos, com o objetivo de apontar os temas recorrentes e a proximidade do uso da língua escrita com o português brasileiro, apesar do uso da segunda pessoa do singular com sua respectiva forma verbal. A transcrição, como as portuguesas, obedece ao original, com os equívocos gramaticais e indicação apenas das iniciais dos nomes.

Há poucas marcas de autoria; elas se restringem, em alguns momentos, às escolhas do que será dito dentro dos temas previamente eleitos. Basicamente as crianças elegeram os mesmos temas: apresentạção pessoal, a escola, a professora, o país e o seu povo, supostamente após interlocução na sala de aula sobre os conteúdos necessários a uma carta pessoal para um colega que vive em um país do outro lado do óceano Atlântico. No processo de apropriação da estrutura da carta, da sua finalidade, de sua composição, as crianças deixam aflorar suas hipóteses. $\mathrm{Na}$ primeira, que vem a seguir, I coloca seu nome logo após a data, como fazem todos os aprendizes desse gênero porque, para eles, pôr seu nome no final impediria o destinatário de saber a identidade do enunciador, por_estarem acostumados, apesar de recém-chegados ao mundo da escrita, com a leitura linear dos textos. Os alunos irão aprender que cada gênero solicita uma abordagem diferente do leitor, como a carta, cuja segunda ação, após a leitura de local, data e vocativo, será a de ler a última palavra, no final: o nome do enunciador.

Eis a carta de $\mathbf{I}$ :

Luanda, 17 de maio de 2009

Nome: I.E.N.S.

Olá, amiga J.M.

Como estás?

Sou aluna da professora A, tenho 8 anos de idade, estudo a $3^{\text {a }}$ Classe, na escola 2004, situada no bairro Alvalade, 
na cidade de Luanda, capital de Angola, que é um país de África. Somos 33 alunos na minha turma. Gostaríamos de ver também vossas fotografias. Temos 7 a 8 anos de idade e somos negros na sua maioria, mais também temos colegas brancos e achocolatados. Temos cabelos pretos e castanhos, somos inteligentes, mais há aqueles colegas preguiçosos. Eu sou inteligente, gosto de ler e estudar. E tu és inteligente? Gostas de estudar e de ler? Gosto de saber o que se passa no meu país, por isso ouço notícias pela televisão e rádio.

Aguardo ansiosa pela sua resposta. Um grande abraço. Beijos.

Os demais colegas de I, como ela mesma, enviaram suas fotos e fizeram uma autodescrição, com ênfase nas cores da pele, manifestando a intenção de marcar claramente sua proximidade com as cores do povo brasileiro, criadas pelos próprios brasileiros em suas relações culturais. I apresenta uma característica particular: em vez de interessar-se pelos programas infantis da TV, opta por noticiários e pela audiência do rádio, hoje tão pouco comum entre as crianças brasileiras. Em oposição a I, seu colega $\mathbf{E}$ afirma: “Adoro os programas da vossas televisão: A Xuxa, sítio do Pica-Pau- amarelo. Tchau e um beijo para todos e até aproxima."

Como I, E utiliza-se de termos mais próximos da forma como se expressam os alunos brasileiros - como se pode observar na afirmação de E: "Tchau e um beijo para todos e até aproxima (sic)", possivelmente por influência de programas televisivos brasileiros difundidos pela TV angolana. Toda forma de contato humano exerce influência em nosso processo de desenvolvimento das formas superiores de condutas. O outro com quem nos relacionamos pode estar próximo ou distante, mas sempre ao alcance da possibilidade de mantermos com ele um diálogo. Como nos assegura Vygotsky, "por trás de todas as funções superiores e suas relações se encontram geneticamente as relações sociais, as autênticas relações humanas" (VYGOTSKY, 2000, p. 150). 


\section{Conclusão}

O desenvolvimento das atividades pedagógicas, na área de aquisição da leitura e da escrita com as cartas internacionais atribuiu valor às manifestações sociais, especificamente com a cultura popular, cultura escolar e costumes próprios da população. As cartas portuguesas, mais que as angolanas, circunscritas ao âmbito das apresentações, avançaram sobre jogos, brincadeiras, festas e culinária.

Essas ações de escrever para o outro, bem definido, orienta o aluno, no processo inicial de apropriação da escrita, para a escolha dos temas, do estilo, das palavras e da composição dos enunciados e, neste caso, promovem a disseminação e intercâmbio dos traços culturais por meió da sua inserção em mundo além da escola, de sua cidade e de seu país. A apropriação da língua como um ato discursivo em realização no seio das relações humanas faz da velha correspondência pessoal um instrumento poderoso de evolução no domínio da língua escrita.

Nesse processo de crescente autonomia no domínio da modalidade escrita de linguagem, a tensão entre assumir a autoria e renunciar a èla, no contexto da aprendizagem escolar, está presente na maioria das cartas, coletivas ou individuais. É preciso considerar, porém, que a fase inicial do processo de aprendizagem da língua, pelo fato de a criança ainda não escrever convencionalmente, é, via de regra, conduzida com maior diretividade pelo professor. Isso ficou evidente nos exemplos das cartas coletivas, em que a condução da escrita foi feita pela professora da sala, que imprimiu a elas maior grau de formalidade que a existente nas cartas dos alunos que, apesar de terem passado pela correção da professora, conservaram as escolhas originais dos alunos quanto à forma de expressão.

Estão ainda inseguros, nesse processo, os elementos composicionais do gênero - a hierarquia dos dados, as relações espaciais, os temas, indicados pela alternância entre enunciados de informação e de indagação. 
A prática de escrita de textos como processo dialógico pode levar à superação dessas dificuldades.

Em tempos de investimento em ações de internacionalização das universidades, soa curioso o fato de crianças pequenas, de 8 anos, em países de mesma língua, penetrarem, pela escrita, em mundos linguisticamente próximos, mas culturalmente afastados; em suma, internacionalizarem-se por meio de uma ação de extensão e de pesquisa de uma universidade pública.

\section{Referências bibliográficas}

BAKHTIN, M.. Marxismo e filosofia da linguagem. São Paulo: Hucitec, 1990.

Estética da criação verbal. São Paulo: Martins Fontes, 2003.

CARR, W; KEMMIS, S.. Teoria crítica e la enseñanza: La investigạciónacción en la formación del profesorado. Trad. J. A. Bravo. Barcelonạ: Martins Roca, 1988

SANTOS, S. O.. Cartas pessoais: uma das portas para a inserção da criança no mundo da cultura escrita. 2010. 140f. Trabalho de conclusão de Curso (Licenciatura em Pedagogia) - Faculdade de Filosofia e Ciências, Universidade Estadual Paulista, Marília, 2010.

THIOLLENT, M.. Metodologia da pesquisa-ação. São Paulo: Cortez, 1986.

TRIPP, D.. Pesquisa-ação: uma introdução metodológica. Revista Educação e Pesquisa. São Paulo, v. 31, n. 3, p. 443-466, set. /dez. 2005.

VYGOTSKY, L. S.. A construção do pensamento e da linguagem. São Paulo: Martins Fontes, 2001.

Génesis de las funciones psíquicas superiores. In: Obras escogidas. Tradução de Lydia Kuper. Moscou: Visor, 2000, p. 139168. 


\section{Autores:}

Dagoberto Buim Arena

Professor do Departamento de Didática e do PPGE da UNESP/Marília Contato: arena@marilia.unesp.br

Sonia Oliveira Santos

Graduada em Pedagogia da UNESP/Marília

Contato: Soniliver.ped@ marilia.unesp.br

Stela Miller

Professora do PPGE da UNESP/Marília

Contato: stelamil@terra.com.br

Texto recebido em novembro de 2011.

Texto aprovado para publicação em janeiro de 2012.

\section{Como citar este texto:}

ARENA, D. B.; SANTOS, S. O.; MILLER, S.. Cartas pessoais entre crianças brasileiras, portuguesas e angolanas. Revista Acolhendo a alfabetização nos países de língua portuguesa, Brasil, São Paulo, volume 1, $\mathrm{n}^{\mathrm{o}}$. 12, p. 108 - 131 , Mar. 2012. Disponível em: <http://www.acoalfaplp.net>. 